Journal of Advanced Research in Fluid Mechanics and Thermal Sciences

Journal homepage: www.akademiabaru.com/arfmts.html ISSN: 2289-7879

\title{
Evaluation of the Potential of Renewable Thermal Energy from Shingles Using Thermoelectric Generator (TEG) for Residential Use Application
}

\author{
Wan Akashah Wan Jamaludin ${ }^{1}$, Muhammad Akmal Johar ${ }^{1,}$, Omar Mohd Faizan Marwah ${ }^{1}$, Azriszul \\ Mohd Amin ${ }^{1}$
}

1 Faculty of Mechanical \& Manufacturing Engineering, Universiti Tun Hussein Onn Malaysia, 86400 Parit Raja, Johor, Malaysia

\begin{tabular}{|c|c|}
\hline ARTICLE INFO & ABSTRACT \\
\hline $\begin{array}{l}\text { Article history: } \\
\text { Received } 12 \text { January } 2020 \\
\text { Received in revised form } 26 \text { February } 2020 \\
\text { Accepted } 26 \text { February } 2020 \\
\text { Available online } 26 \text { April } 2020\end{array}$ & $\begin{array}{l}\text { A thermoelectric generator (TEG) using Seebeck effect to generate electrical energy in } \\
\text { a residential application encompasses a case study of a test rig consisting of a concrete } \\
\text { shingle as case study material. This paper explores its behavior and response to } \\
\text { changes in temperature throughout the day. Four TEGs in series are mounted on the } \\
\text { underside of a shingle. The measurement of the voltage and current response were } \\
\text { made to determine the power generated. Using National Instruments as a data } \\
\text { acquisition device with thermocouple probes to gather all the necessary data of which } \\
\text { are discussed in the paper. From the experiments, the modules were able to generate } \\
\text { up to } 65.22 \mu \mathrm{W} \text { at } 138 \Omega \text {. This shows a considerable potential of TEG application in } \\
\text { residential areas, as they are scalable. }\end{array}$ \\
\hline
\end{tabular}

Keywords:

Thermal energy generator (TEG); TEG materials; TEG Application; Experiment and Simulations

Copyright @ 2020 PENERBIT AKADEMIA BARU - All rights reserved

\section{Introduction}

Thermoelectric generator (TEG) in Figure 1 is commonly used in high thermal difference application such as geothermal [1]; a steady source of heat available to generate the thermal difference, similarly in thermal recovery in Rankine engine [2]. Temperature difference and the amount of heat available are essential as the output power generated is dependent on those parameters [3]. Even though the physics principle of converting thermal difference into electricity has been established since 1800s, there is still no products or applications available in mass-market exploiting this renewable energy potential in the shingle solar sector. One of the reasons is due to low power generation and efficiency in the TEG itself.

\footnotetext{
* Corresponding author.

E-mail address: akmal@uthm.edu.my (Muhammad Akmal Johar)
}

https://doi.org/10.37934/arfmts.70.2.5058 
Research trends in the TEG studies are mostly targeted towards high-temperature applications such as tapping waste heat from car engine [4]. For lower temperature areas the research focusing on a hybrid application such as incorporating it with solar technology as photovoltaic/thermal energy generator (PV/TEG) [5] and in heating, air conditioning and ventilation (HVAC) as means to make use of the exhaust airflow that else will be wasted heat evacuated to the environment as a source of energy to be recovered and from that to provide support to the HVAC system in the form of preheating and electrical energy generation [6], whilst journal like Jamal Abed et al., [7] does not contain a TEG in the study, but the publication is in parallel and have potential to implement the latter system based on the performance data provided by the journal's author.

Moreover, studies regarding control and current TEG application are too looked into such as an experiment on a floating TEG system as means of an energy harvesting system [8] and controls used in photovoltaic technology as TEG system are closely related to it than any other renewable energy method, controls used in solar technology to provide maximum energy generation is the maximum power point tracker (MPPT) this is key factor as a steady output is required but the input is changing according to the weather condition $[9,10]$. Similar to solar, minor improvements and performance tweaks to gain higher efficiency are too observed such as in research of Ibrahim et al., [11], improving the thermal conductivity of water by suspending thermally conductive particles, as Salleh et al., [12] which improve the latter with an addition of copper into the mix.

This paper is reporting on a case study result that is evaluating the feasibility of using a TEG in electricity generation from concrete shingles on a residential roof application. Previous research has shown the potential to harness the thermal energy from the roof up to $75^{\circ} \mathrm{C}$ on the shingle surface temperature, has been recorded during a hot day [13]. The next step is to establish the amount of electric power output that can be generated from the study of TEG on concrete shingle consisting of a test rig to house a data acquisition device with measuring equipment to sample data from the shingle environment and the TEG environment.

Concerns on reducing the impact of a community's carbon footprint is critical and even optimizing the current energy usage in buildings are scrutinized in research by Awang et al., [14], not only energy usage is critical to a building's efficiency. The construction and insulation also plays a major role in reducing thermal losses by containing the room at a set temperature hence saving energy used in thermal regulation [15]. Which is in line with the goal of this research as means to contribute on improving the overall building efficiency albeit by reducing the amount of energy absorbed by the roof into a usable electric source.

\section{Methodology}

Method of approach via test rig is the most viable option as ease of access to the roof will be difficult and mounting a custom made shingle that will house the TEG require removal of roofing material which poses a problem for a small scale case study. However, such a problem will have to be overcome in testing for a large scale operation for the scalability studies. Next, the data gathered is a crucial part of this case study to provide all the data required to validate or support the application of TEG in residential use. The collected data are in the form of temperature, voltage, and current. Heat is the critical point as it is the primary driver to the whole operation. Hence the need to collect at different points of data via temperature probes for ambient and TEG temperature data is required. Voltage and current generated by TEG are also crucial in the study to provide data to correlate the temperature readings. Enabling to determine the effect of temperature amplitude and its changes to the output of the TEG. 

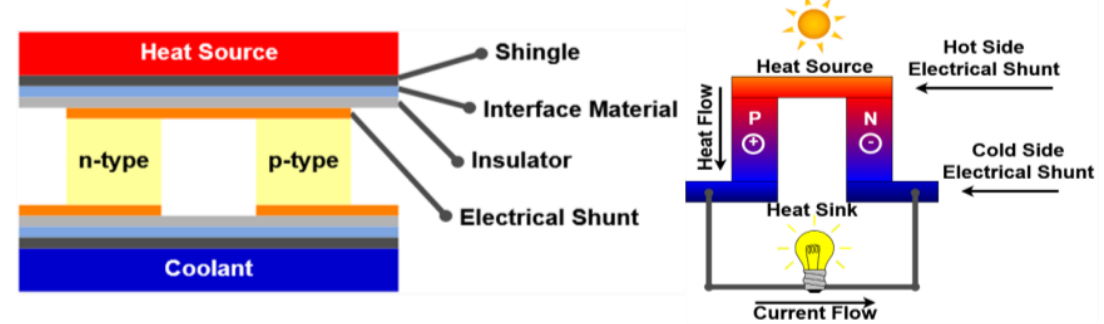

Fig. 1. Cross section of a TEG construction and Seebeck effect

\subsection{Data Acquisition Test Rig}

A test rig has been developed to measure the actual performance of the power generation of TEG in a real situation based on location and environmental condition. This will provide the necessary data to conclude the feasibility study, with the use of a data acquisition unit from National Instruments. Figure 2 showed two thermocouple modules of NI 9211 for the TEG and ambient probe, NI 9201 for voltage measurement module and NI 9203 current module. A computer interface has been developed to show the real-time data recorded during the process.

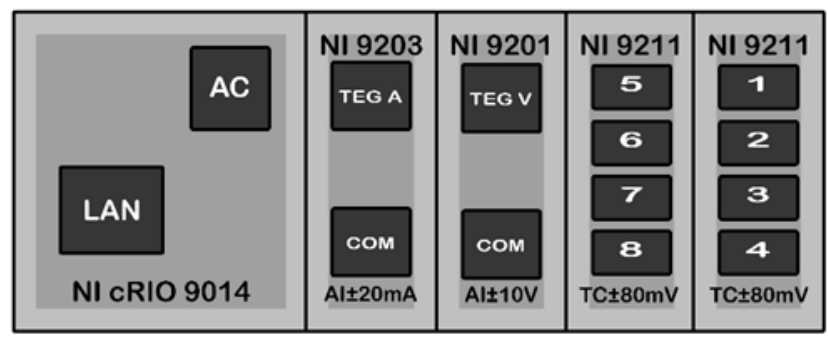

Fig. 2. NI DAQ modules for measuring temperature, current and voltage produced by TEGs

\subsection{Shingle Setup}

Figure 3 shows the data compiled from the test rig data obtained from the shingle. Figure 4 showing the position of one of the locations for the ambient probe in the DAQ system Concrete shingle, commonly used in residential homes are mounted with TEG (Figure 4) as to provide the data in the experiment. In total, the temperature is measured at three different areas, which are the hot and cold side of TEG, and the ambient temperature. While the current and voltage generated were measured across the TEG.

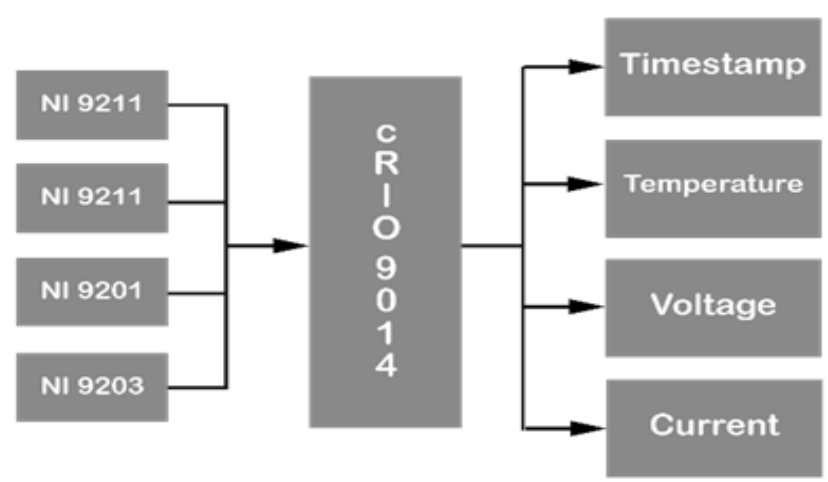

Fig. 3. $D A Q$ block diagram for measuring temperature, current and voltage produced by TEGs 
The temperature and power generation were measured between 8.00AM till 6.00PM. This range was selected due to the optimal sunlight condition of the day.

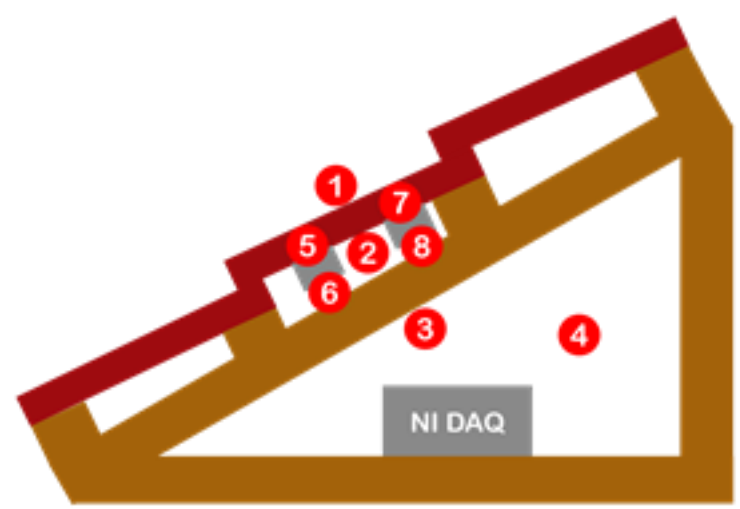

Fig. 4. Temperature probe positioned at the top of the roof to measure ambient temperature and TEG placed at the bottom

8th April Whole-day Temperature

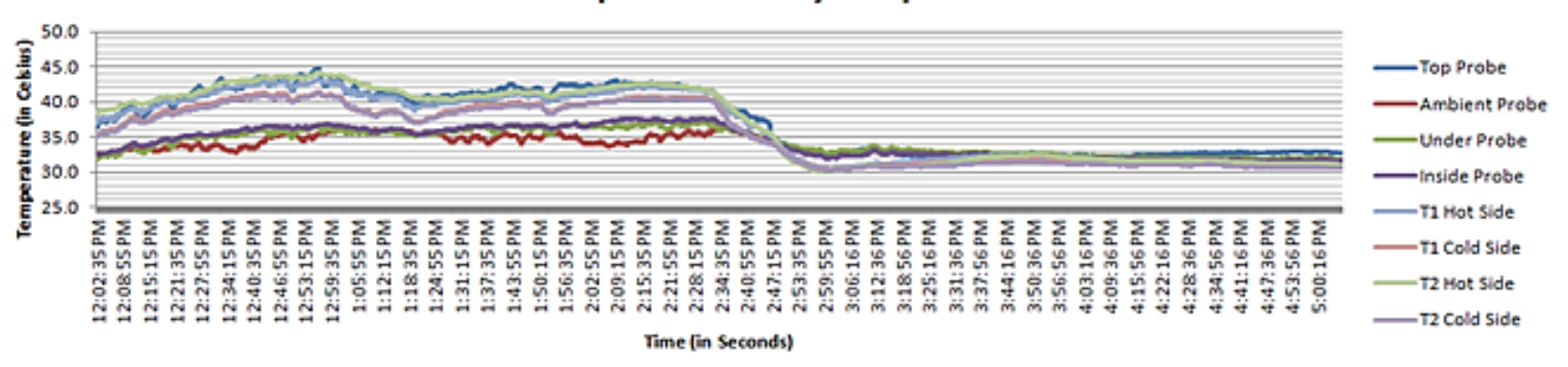

8th April Whole-day Voltage and Current

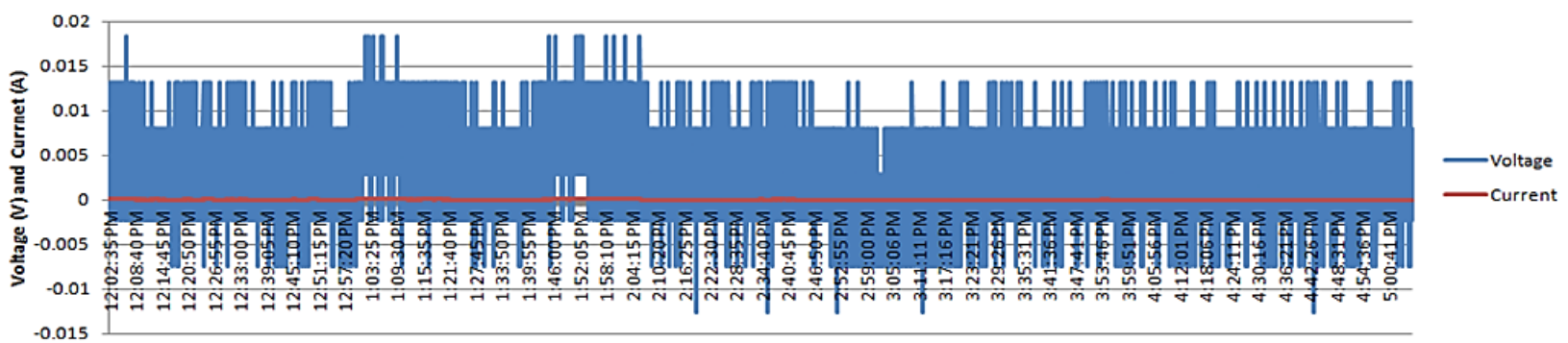

Fig. 5. Whole day temperature, voltage and current measurement of 8th April 2018

\subsection{Results and Discussions}

The amount of raw data obtained are plenty over the course of a 7-day data acquisition process. Analyzing raw data alone does not give much insight into how the temperature affects the output of TEG. Figure 5 shows the raw data that requires further processing in order to see any pattern of it. $A$ recent research report Man et al., [9] relating to shingle study proposed a classification of weather condition based on temperature range, as shown in Table 1. However, this proves difficult to be used as a weather identifier since the measurement was made based on direct sunlight condition only. Hence, an improvement on the method by observing the graph slope in response to weather pattern.

Using weather pattern identifier with raw data are impossible due to the fluctuation in the data hence, the filtered data is to take the sample at 10-minute intervals as to minimize the data points but still give relevant patterns to be observed and to take note upon. 
Table 1

Weather pattern temperature range

\begin{tabular}{ll}
\hline Condition & Temperature \\
\hline Sunny & $>50$ \\
Cloudy & $31-49$ \\
Rainy & $<31$ \\
\hline
\end{tabular}

Table 2

Weather pattern classification

\begin{tabular}{lll}
\hline Date & Label & Avg. Temperature \\
\hline $8^{\text {th }}$ April & Rainy & 32 Outside; 42 TEG \\
\hline $9^{\text {th }}$ April & Rainy & 32 Outside; 39 TEG \\
\hline $16^{\text {th }}$ April & Cloudy & 32 Outside; 46 TEG \\
\hline $17^{\text {th }}$ April & Cloudy & 35 Outside; 43 TEG \\
\hline $22^{\text {nd }}$ April & Rainy & 35 Outside; 46 TEG \\
\hline $25^{\text {th }}$ April & Sunny & 36 Outside; 49 TEG \\
\hline $26^{\text {th }}$ April & Sunny & 37 Outside; 49 TEG \\
\hline
\end{tabular}

\subsection{Weather Pattern Identifier}

A weather pattern identifier is proposed to improve the readability and accurate determination of weather pattern, by not only using temperature but graph slope also as Table 2 shows the implemented identifier, if it was to use the method without the improvement all the data would fall under cloudy day category.

A sunny day identifier is due of the positive slope and temperature of greater than $50^{\circ} \mathrm{C}$ as shown in Figure 6, despite slope after 1.10 PM indicates a cloudy condition due to the gentle declining gradient the temperature before it was greater than $50^{\circ} \mathrm{C}$ and sustained indicating a sunny day. $\mathrm{A}$ cloudy day identifier Figure 7 shows the declined gradient as well as not peaking above $50^{\circ} \mathrm{C}$ throughout the day. Figure 8 shows a rainy day identifier as the sharp gradient apparent at 1.20 PM with temperatures not maintained steady throughout the day and only peaked at $50^{\circ} \mathrm{C}$ just before the rain is due.

Filtered Temperature

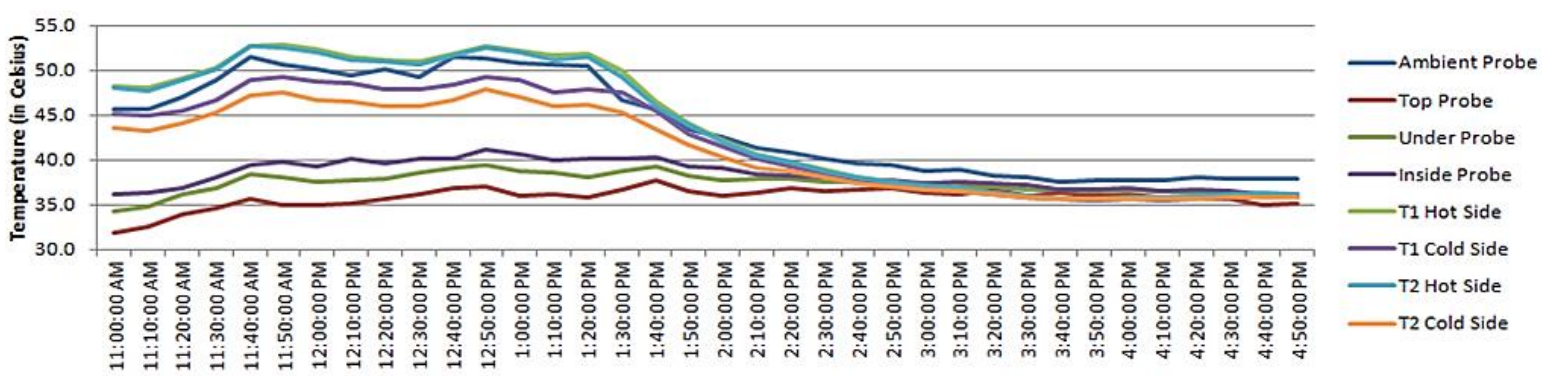

Fig. 6. Sunny day temperature graph 
Filtered Temperature

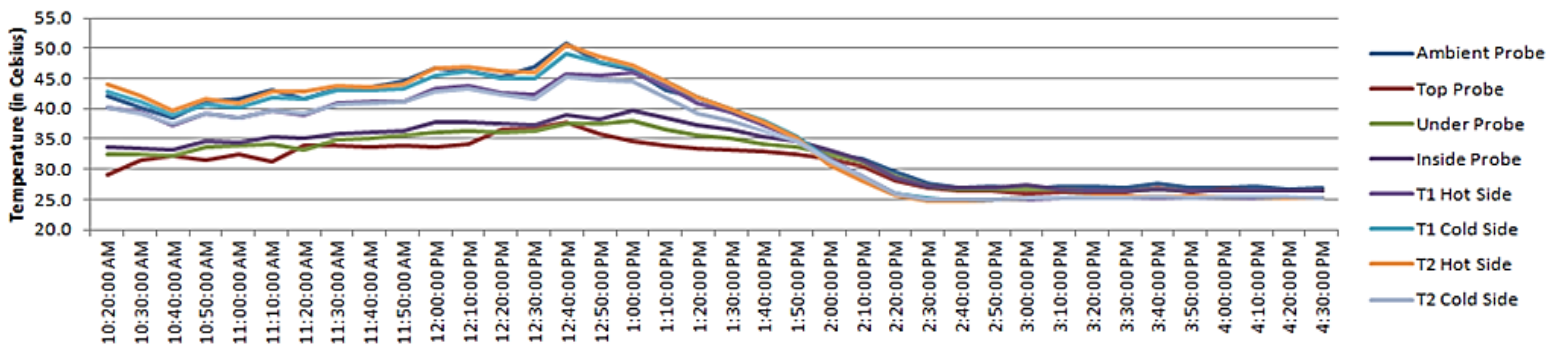

Fig. 7. Cloudy day temperature graph

Filtered Temperature

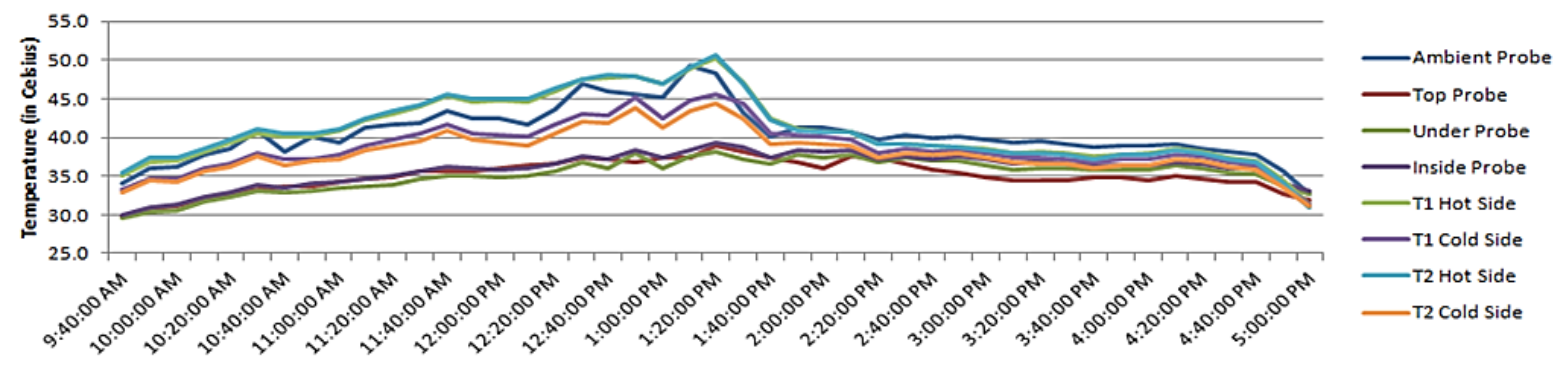

Fig. 8. Rainy day temperature graph

\section{TEG Responses and Behavior}

Proving the feasibility of TEG for residential application require weather data analysis and TEG data to correlate a definitive performance criterion faced using concrete shingle as the medium to extract the latent heat of the sun for the TEG to generate its electrical energy.

Figure 9 and Figure 10 show a phenomenon that was anticipated with the use of a concrete shingle of which is a response lag, the thermal change does not affect the energy generation until 20 minutes have passed, and these are consistent with all other 7 days data.

As for Figure 10, another problem highlighted when working with constantly changing weather condition, that is thermal inconsistency will lead to hysteresis in the voltage generated as it is unable to generate a steady output source. This, in turn, will affect the power generated as the DAQ uses a fixed resistor of $138 \Omega$.

Highlighted in the previous mention, an unstable source of heat will cause instability in the output, but if a steady source of heat energy is maintained, an equal output will follow suit as in Figure 11 a steady thermal gradient able to generate a sustained $0.003 \mathrm{~V}$ output for 40 minutes.

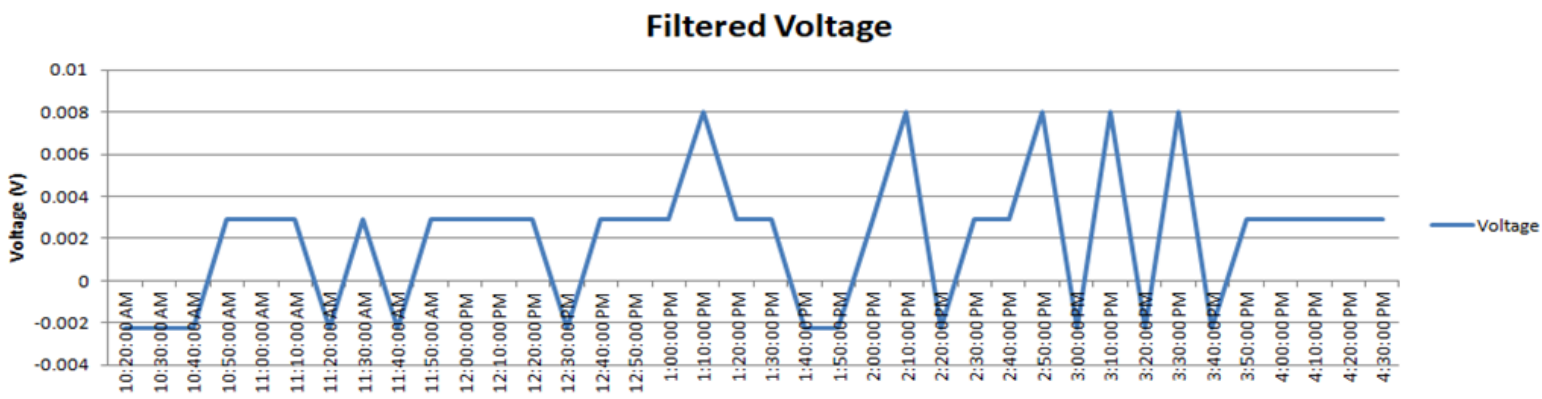

Fig. 9. Cloudy day voltage graph with 10-minute interval 


\section{Filtered Temperature}

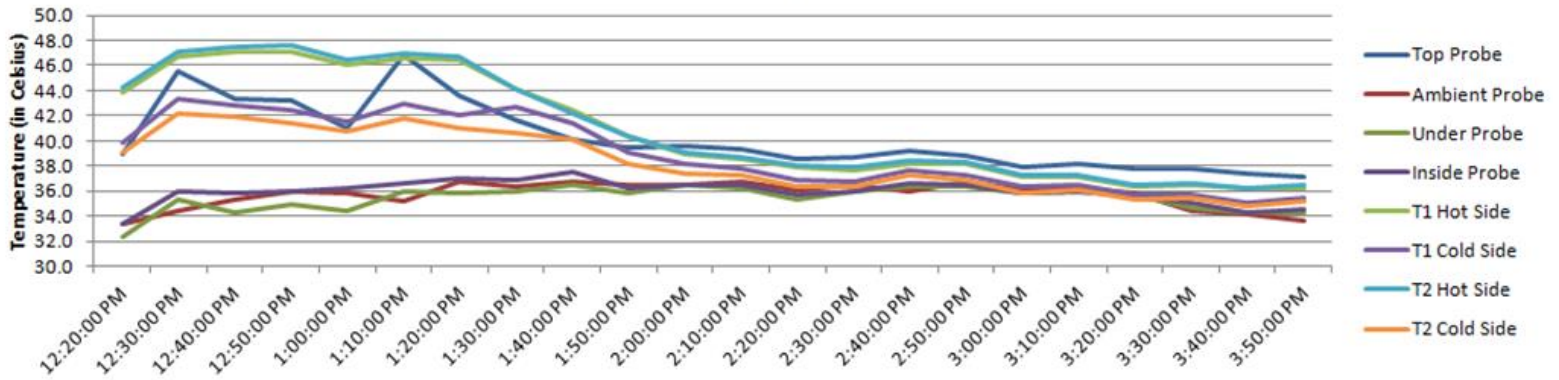

Fig. 10. 17th April 10-minute interval temperature

\section{Filtered Voltage}

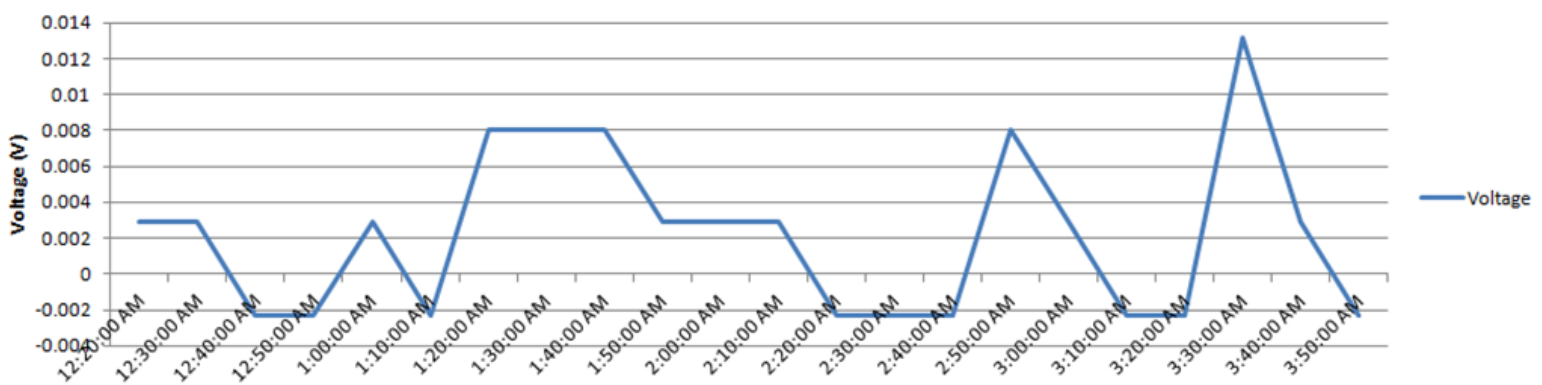

Fig. 11. 17th April 10-minute interval voltage graph

Highlighted in the previous mention, an unstable source of heat will cause instability in the output, but if a steady source of heat energy is maintained an equal output will follow suit as in Figure 17 a steady thermal gradient able to generate a sustained $0.003 \mathrm{~V}$ output for 40 minutes.

\subsection{TEG Performance Analysis}

Despite the data collected and the experiment showed potential output, performance improvements on TEG side is required. Observing all temperature graph Figure 12 to Figure 13, the thermal difference on shingle and ambient able to reach $10^{\circ} \mathrm{C}$ whilst on the TEG hot side and cold side difference of only $3^{\circ} \mathrm{C}$. This could be one of the factor that could be improved as there are limits to passive cooling, TEG efficiency and energy generation is dependent on the thermal difference. The current thermal difference of TEG using passive cooling is $\Delta T$ TEG $<\Delta T$ shingle whilst the ideal condition is for the thermal difference between the hot side, and the cold side is $\Delta T$ TEG $=\Delta T$ shingle.

\section{Filtered Temperature}

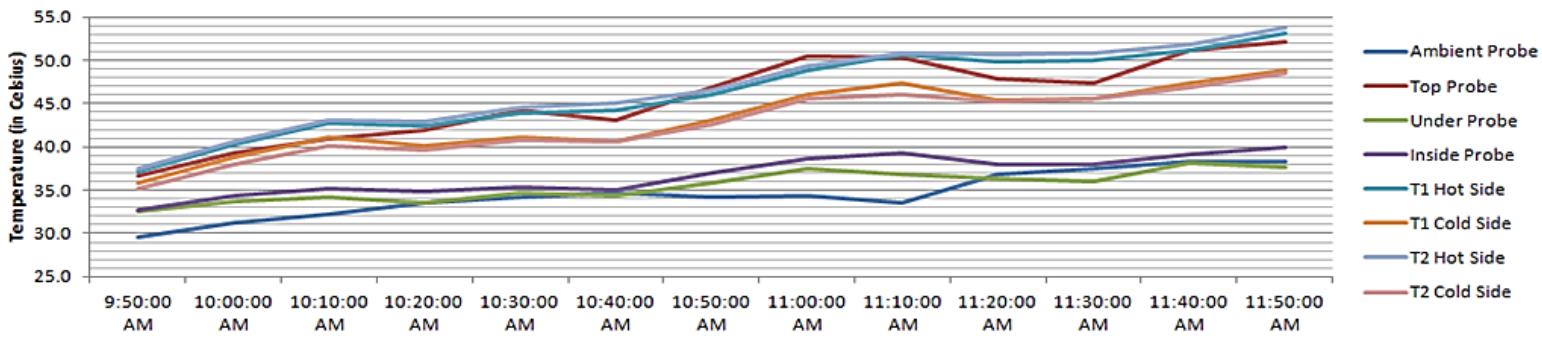

Fig. 12. 26th April 10-minute interval temperature 


\section{Filtered Voltage}

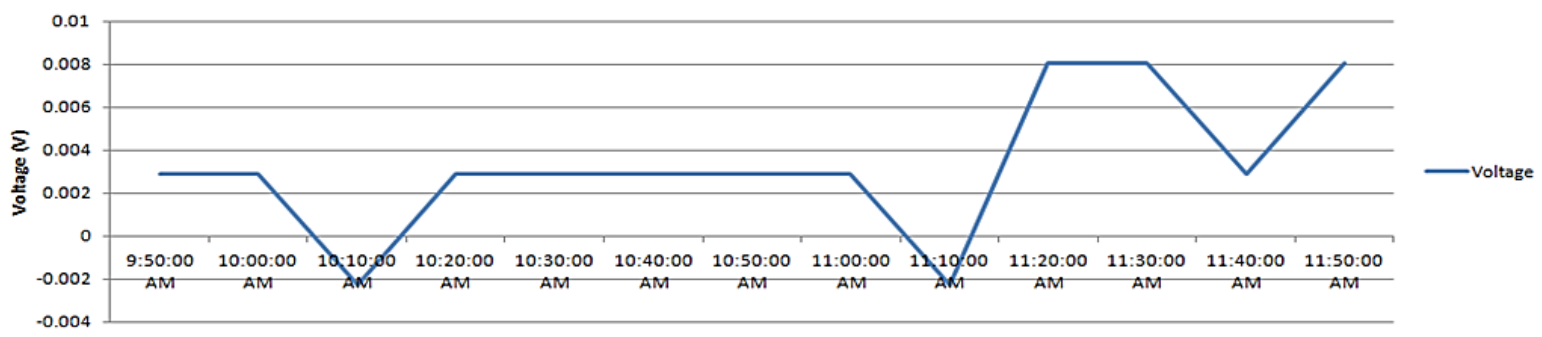

Fig. 13. 26th April 10-minute interval voltage graph

\section{Conclusion}

Based on the extracted data from all 7 days, the TEG system with 4 modules in series is able to generate on average $0.003 \mathrm{~V}$ at $138 \Omega$ resistance, which equates to $65.22 \mathrm{uW}$. This shows that it is feasible to obtain electrical energy from such construction. However, further research in the application field regarding micro energy generation for TEG is required as to further understand the potential and future of TEG as a viable and cost-effective, maintenance-free system of an energy generation system that could be placed and will reliably generate energy for up to 25 years free of maintenance.

\section{Acknowledgement}

This research is supported by FRGS grant under Vot K108.

\section{References}

[1] Liu, Changwei, Pingyun Chen, and Kewen Li. "A 1 KW thermoelectric generator for low-temperature geothermal resources." In Thirty-ninth workshop on geothermal reservoir engineering, Stanford University, Stanford, California, pp. 24-26. 2014.

[2] Islam, Salmah Md Saiful, and Syamimi Saadon. "Performance Analysis of Supercritical Organic Rankine Cycle System with Different Heat Exchangers Design Configuration." Journal of Advanced Research in Fluid Mechanics and Thermal Sciences 65, no. 2 (2020): 324-333.

[3] Snyder, G. Jeffrey. "Thermoelectric energy harvesting." In Energy Harvesting Technologies, pp. 325-336. Springer, Boston, MA, 2009. https://doi.org/10.1007/978-0-387-76464-1 11

[4] Champier, Daniel. "Thermoelectric generators: A review of applications." Energy Conversion and Management 140 (2017): 167-181. https://doi.org/10.1016/j.enconman.2017.02.070

[5] Ariffin, M. Ruzaimi, S. Shafie, W. Z. W. Hassan, N. Azis, and M. Effendy Ya'acob. "Conceptual design of hybrid photovoltaic-thermoelectric generator (PV/TEG) for Automated Greenhouse system." In 2017 IEEE 15th Student Conference on Research and Development (SCOReD), pp. 309-314. IEEE, 2017. https://doi.org/10.1109/SCORED.2017.8305373

[6] Ramadan, Mohamad, Samer Ali, Hasan Bazzi, and Mahmoud Khaled. "New hybrid system combining TEG, condenser hot air and exhaust airflow of all-air HVAC systems." Case Studies in Thermal Engineering 10 (2017): 154160.

https://doi.org/10.1016/j.csite.2017.05.007

[7] al Wahid Jassim, Jamal Abed, Susan Abed Hassan, and Baydaa Hussain Maula. "Design of Wind Catcher for Earth Air Heat Exchangers to Rationalize Energy Consumption." Journal of Advanced Research in Fluid Mechanics and Thermal Sciences 65, no. 2 (2020): 286-294.

[8] Singh, Jaspreet, Parth Kuchroo, Hemant Bhatia, and Ekambir Sidhu. "Floating TEG based solar energy harvesting system." In 2016 International Conference on Automatic Control and Dynamic Optimization Techniques (ICACDOT), pp. 763-766. IEEE, 2016. https://doi.org/10.1109/ICACDOT.2016.7877689 
[9] Man, E. A., D. Sera, L. Mathe, E. Schaltz, and L. Rosendahl. "Dynamic performance of maximum power point trackers in TEG systems under rapidly changing temperature conditions." Journal of Electronic Materials 45, no. 3 (2016): 1309-1315.

https://doi.org/10.1007/s11664-015-4015-y

[10] Dalala, Zakariya M. "Energy harvesting using thermoelectric generators." In 2016 IEEE International Energy Conference (ENERGYCON), pp. 1-6. IEEE, 2016. https://doi.org/10.1109/ENERGYCON.2016.7514088

[11] Ibrahim, Zainab Ali, Qusay Kamil Jasim, and Adnan Mohammed Hussein. "The impact of alumina nanoparticles suspended in water flowing in a flat solar collector." Journal of Advanced Research in Fluid Mechanics and Thermal Sciences 65, no. 1 (2020): 1-12.

[12] Salleh, Siti Nur Alwani, Norfifah Bachok, Norihan Md Arifin, and Fadzilah Md Ali. "Effect of Buoyancy Force on The Flow and Heat Transfer Around a Thin Needle in Al2O3-Cu Hybrid Nanofluid." CFD Letters 12, no. 1 (2020): 22-36.

[13] Johar, Muhammad Akmal, Zulkarnain Yahaya, Omar Mohd Faizan Marwah, Wan Akashah Wan Jamaludin, and Mohamed Najib Ribuan. "Feasibility study of Thermal Electric Generator Configurations as Renewable Energy Sources." In Journal of Physics: Conference Series, vol. 914, no. 1, p. 012024 . IOP Publishing, 2017. https://doi.org/10.1088/1742-6596/914/1/012024

[14] Awang, Mariah, C. S. Tham, Nurhanis Mohd Basir Ruddin, Mohamad Ashraf Abdul Rahman, Nuramidah Hamidon, Faridahanim Ahmad, Kamaruzaman Musa, Sasitharan Nagapan, and Mohd Shahril Abdul Rahman. "Assessment of Energy Saving Potential and Lighting System in Teaching Building." Journal of Advanced Research in Fluid Mechanics and Thermal Sciences 65, no. 1 (2020): 159-169.

[15] Muhieldeen, Mohammed W., Q. Y. Wong, Ummi Zulaikha Abd Rahman, and Wah Yen Tey. "Energy Saving by Applying Different Wall Thermal Insulations on a Room at Malaysian Institution." Journal of Advanced Research in Fluid Mechanics and Thermal Sciences 65, no. 1 (2020): 130-139. 